Serviço de Clinica Medica do Prof. Rubião Meira

\title{
Sobre um caso de tumor do mediastino
}

\author{
Bernardino Tranchesi e Felipe Fanganielo \\ (Doutorandos).
}

0 caso de que nos iremos ocupar foi por nós observado e estudado na Enfermaria do Prof. Rubião Meira (11." M.H.), entre os leitos que estão sob os cuidados do Dr. Jairo Ramos. Embora não constitua uma raridade morbida, presta-se, contudo, a algumas considerações interessantes, principalmente, no que diz respeito á propedeutica do mediastıno. Os ensinamentos que o caso nos of ereceu ficaram perfeitamente concretisados, porquanto o acompanhamos até á mesa de necropsia.

A nossa exposição ficará, exclusivamente, estricta ao terreno da semiologia, que encontra, na sindrona de compressão mediastinal, sintomas e sinais tipicos e precisos, torliando o diagnostico bastante facil. De fáto, o amplo espaço compreendido entre as duas pleuras, apresenta pela natureza e correlação dos numerosos orgãos que encerra, uma semiotica clara, conhecida já de ha muito. Os antigos clinicos, encabeçados por Cardarelli estabeleceram, graças á sua intuição, os fundamentos do exame clinico do mediastino com tal precisão que até hoje não sofreram modificaçōes.

Não abordaremos a questão da natureza e origem dos tumores mediastinais, que, se em certas eventualidades ficam claramente estabelecidas, em outras deixam duvidas mesmo ao anatomo-patologista.

Passaremos, agora, á leitura da observação, para em seguida discutir o diagnostico e dizer algumas palavras á respeito da evolução e necropsia do caso.

(*) Apresentado ao Departamentu silentiflco do Centro Academico -Oewaldo Cruz", em 16 de slaio de 1936. 
1. S 30 nos casado, Inurador, estoniano, domicillo e procedencia infulal. Deu entrada no servico em 3 de Abril de 1835, dlecndo estar dixple ha 3 mezes e queixando-se de sulocaçóo e Inchasn do lorax, pescoso c cabera. Seus males se inicinram por ligerro canseco em cerlos trabalhos que o docnte sempre fizera sem nada ernlir. Sentia entáo lilla de ar a sufocacảo. Apresentava, nessa ocavo. losec sera. Nín sentia palpitaçóes, ou dor precordial, nem apro- ralara edenia. Passou um mez, nessas condiçoes sem ter abandonado - trabalbo. Scu cstado fol, entretanto, depols deste mez, peorando carla ree mais. a ponto de sentir sufocacino mesmo aos menores esforcos. Abase do pescoso inchou-se, tendo o inchaco avançado para a ralurca e lorax. As outras partes do corpo nada sofroram. Ao acordar pela manhd, sentia nào poder abrir os olhos devido ao inchaco, este, confudo. melborava coin o correr do dia. A tosse (1)rnou-se persisten1\%. Irndo aparecido escarrus hemoptoicos uma semana antes de se homplialisar. Nos abaixamentos da cabeca sentia fortes tonturas sendo obrigado amparar-se para nảo cair. A voz se tornou rouca, e, as vezes quando ia falar sentia um aperto, e nảo podia manter converarsto prolongada. Deitava-se em decubito esqurrdo elevado. No decubilo dorsal aumentava a sufocação e no lateral direito, sentia lorte dor no membro superior desse mesmo lado. lleferia o aparecimento de carocos na axila, virilia e regiảo maxilar esquerda. Seu peso díminuira, nào sabendo, informar quanto.

No interrogatorio e antecedentes hereditarios nada havia que pu. desse interesvar. Nos antecedentes pessoais nảo havia passado vene-

(1) que (o) encontrancia, apenas, o fato de ser etilista e tabagista. medicilineo, pesando rado no exame fisico geral? Individuo branco. co lorax o que se tornava, sobrementava cianose da cabeca, pescodellava. As partes laterais sobremaneira evidente quando o doente se res apresentavam-se tum do pescoco, fossas supra e infraclaviculasas supra $e$ infra espinosas lot Narte posterior notavam-se as losbordo costal a pele roseo-vinhosante cheias. Da cabeça até ao reladas. No lurax havia edema discretoresentava venulas muito dilaanda apresentava digno de nolacreto. No restante do corpo a pele parte superior do tronco nota, sendo notavel o contraste entre a licular. Os ganglios cervicais não facto do pescoco. Os axilares, maxilares e ingalpar devido á tumechegando alguns a alcancar o tamanho de um ovo de pomba, todos - percepcéo de ganglios, entretanto, á direiculares era muito dificil im ganglio de limites imprecisos. Esternalgianha-se a impressão de laram.

a sem particularidades. Decubito esquia e tibialgia ausentes. Os exames especiais da cabeca, olbos, nariz elevado. pescoco nảo havia batimentos arteriaissimos locos de infecção. No cula nem estara devido a tumefaçáo. Não se era possivel avaliar de o toras er presente o sinal de Olliver-Cardarelli. ontemente dipo enfisematoso, sendo a respira

Torres ate abdominal ccm 28 excursóes por a respiração predomiso. Egual expansibilidade de ambos os os lados em egual exten- 
raco-vocal mostrava-se diminuido na parte anterior direita e ligeiramente aumentado na parte posterior desse mesmo lado. Massicez do manubrio esternal que produzia no cavo oral som cavitario. Submacicez de todo apice e interscapulo direitos. Hipersonoridade das bases. A ausculta revelou sopro laringo-traqueal sobre o manubrio do esterno. Diminuição da respiraçāo no apice e sopra bronquico no interscapulo.

No exame do coração e vasos havia interessante bradicardia (58 batímentos por minuto). Pressão arterial medida pelo Tycos $120 \times 80$ em ambos os braços. Não havia disigualdade de amplitude dos pul-
tos radiais.

Abdomem e sistema nervoso sem anormalidades.

\section{EXAMES DE LABORATORIO}

Wassermann: negativa.

Ex. urina : negativo.

Exame de sangue realisado pelo Dr. Oria:

Glob. vermelhos: 3.320 .000

brancos: 12.400

Hemoglobina

Valor globular:

$$
\begin{gathered}
66,6 \% \\
1,1
\end{gathered}
$$

\section{Neutrofilos $73,5 \%$}

\section{f bastonetes $1,5 \%$} segmenta dos $72 \%$

Eosinofilos 6,2\%

Basofilos $\quad 0,6 \%$

Linfocitos

$15 \%$

Monacitos e celulas histioides monociticas $4,4 \%$. Endotelios circulantes similes aos da endocardite $40 / 500$.

\section{DISCUSSĀO}

A historia do nosso doente pode ser dividida em dois periodos perfeitamente distintos. Num primeiro periodo o doente começou a notar cansaço em certos trabalhos que sempre executára sem nada sentir. A este sintoma ajuntouse-lhe falta de ar, sufocação e uma tosse seca. Passou assim um mez quando se instalou o segundo periodo caracterizado pelo aparecimento de edema no pescoço, cabeça e torax, assim como de modificaçōes da voz que se tornou rouca, sentindo, tambem, algumas vezes, que não podia manter conversão prolongada por lhe faltar, em determinado momento, a voz. A tosse que aparecera no primeiro periodo da saa molestia tornou-se persistente e acompanhada de escarros hemoptoicos. Pouco antes de dar entrada na enfermaria viu aparecerem tumefações ganglionares indolores em di- 
verans regiỏes do corpo. Este quadro desenrolou-se dentro de um espage de tempo relativamente curto, aproximadamente 3 mezes.

Diante de um desenrolar de fatos dessa natureza nosso raciocinio se inclina, naturalmente, a pensar naqueles tipos de sindruma denominaden de compressio mediastinal. De fato. a clisposiçuo classica do edema, as modificaçôes da voz a lisue secn a persistente, a sufocação aparecendo, principalmenle quando o doente deilava-se, nos fazem pensar em um comprometiment, medinstinal, provavelmente por uma neoplasin in qual as tumefaçỏes ganglionares seriam o reflexo denunciante. Ainda nos detendo mais sobre os dados anamnenlicos, poderemos aquilatar, de um modo geral, da evolucao do processo morhido. () aparecimento insidioso traduzido por ligeira sensaçảo de cansaço aos esforços e tosse, indicava com grande probabilidade uma compressão em inicio, que resançando de modo celere compromeleu a circulação e a respiraça a ponto de determinar edema, sufocação e conpelas tonturas nos cerebrais, este ultimo fenomeno atestado

Os troncos nervosimento da cabeça. cimento progressivo esos, igualinente não escaparam ao creszendo modificações da rapido da inassa compressora, trariur direito. Vemos, portanto, tosse e dores no membro supeelementos fornecidos pela historia jogando, apenas, como os zor que estavamos pela historia da molestia podemos dide compressāo mediastina de um portador de uma sindroma da e trazendo perturbações nervolução mais ou menos rapilare's de grau consideravel. Sempres, respiratorias e vascue de sindroma mediastinal no adulto, se cogita da diagnolugar. pensar em uma formacão lulto, devemos em primeiro quer neoplasica. Eimbora pertença aos lumores vascuaior frequencia, nestes casos, caso escapa a esta regra, pois com, parece-nos que o nosso nunca sentiu dor em qualquer parte bem informou o doente loma que nunca falha nos processos do torax. A dor é o sinsante e tormentasa determinada segundo linuo martelar do ancurisma excitando o puchard pelo conlico, ou pela cxplicaçís de Cardarelli pela plexo nervoso aorletes nervissos pericsarticos. De outro lad pela distensão dos fiisaturrza neoplasica do tumor. pesavam mais a favor da deparamos com una informar. Nos antecedentes do doente 


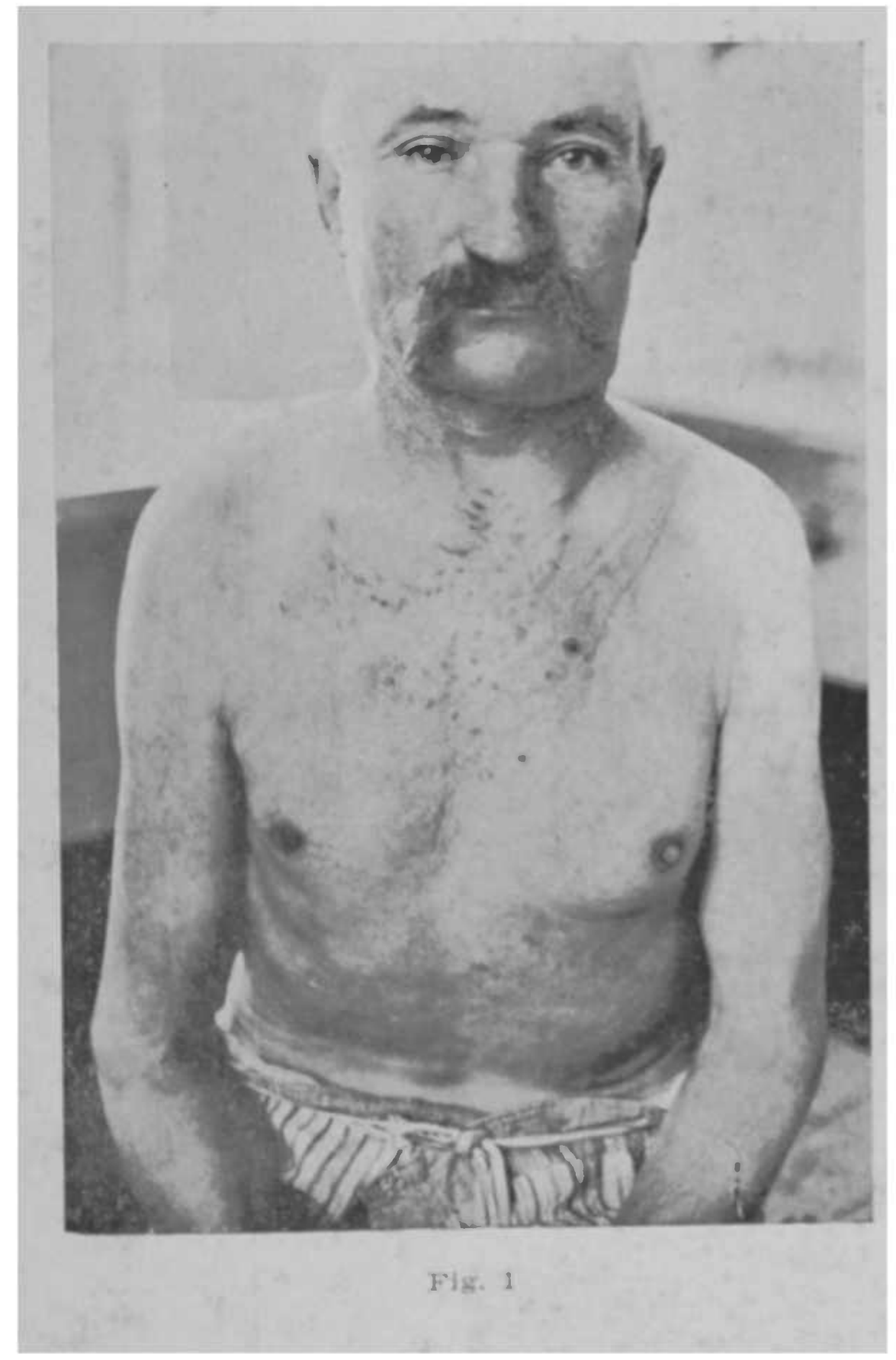




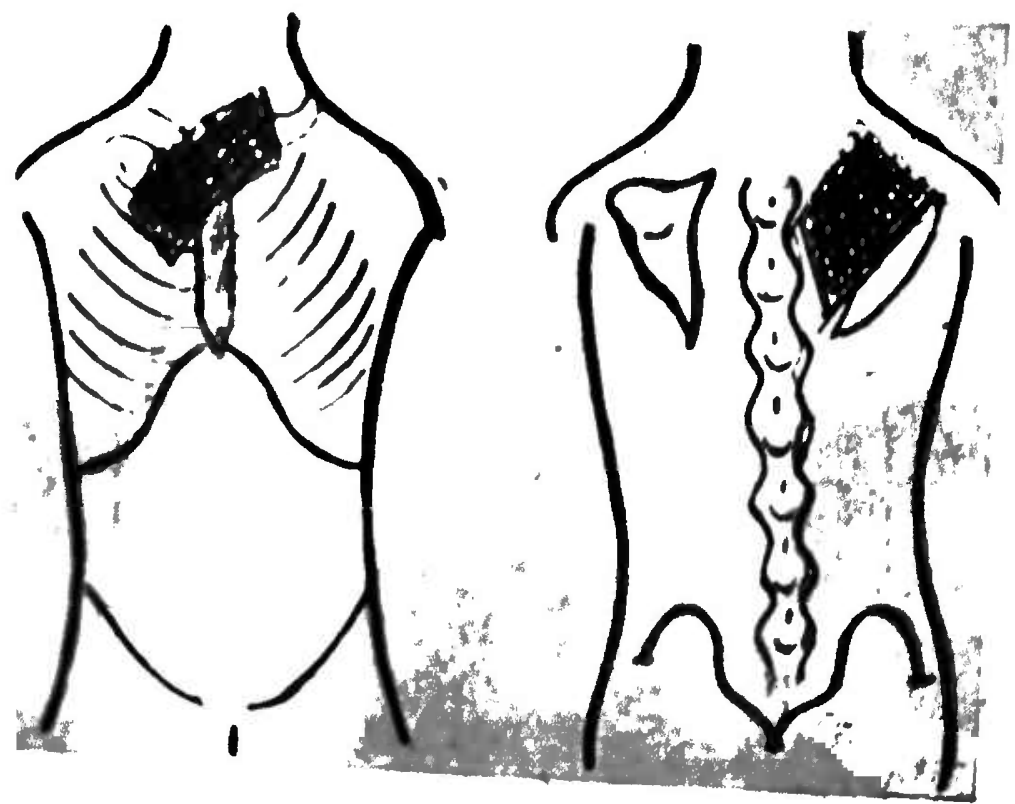

Fig. 2

- Vi. manubio do esterno: - massicez, varlacao de wien. liu fomarn Insing()-traqueal.

abolleto da respiracío

- No pontos

mopero bronquico. 
desde que a consideremos em conjunto a outros dados, a ausencia de passado venereo-sifilitico, que dentro do criterio da relatividade deporia contra aneurisma, que é manifestação vascular da lues terciaria.

No exame geral do doente chamava a atenção o contraste nitido entre a parte superior do corpo edemaciada e cianosada e a parte inferior palida e emagrecida. Esta dispnsição do edema denominado "edema em pelerine" (fig. 1) é classico na obstrução da cava superior. Distingue-se do edema nefritico, angioneurotico e cardiaco pela exclusiva localisação na metade superior do corpo. Algumas vezes, é possivel encontrar na compressão do mediastino, um edema generalisado. Neste caso trata-se de uma insuficiencia cardiaca superveniente ou mais raramente por contemporanea obstrução da cava inferior. Ainda, nestas eventualidades, entretanto, a localisação superior, predomina. No nosso doente não havia, na superficie da pele circulação venosa colateral. 0 que existia, claramente, era a dilatação de pequeninas venulas subcutaneas dadas a grande hipertensão venosa. 0 fenomeno explica-se pela obstrução não completa do vaso, de modo que a retropressão não atingira intensidade suficiente, para vencendo a resistencia das valvulas, obrigar 0 sangue a procurar outra via de escoamento.

Estavamos, portanta em presença de uma estenose cava superior no estadio edematoso, em contraposição ao estadio flebectasico onde predomina o reticulo venoso colateral. A cianose com a mesma localisação do edema mostrava a estase no territorio tributario ao importante tronco venoso. $E^{\prime}$ um sintoma importantissimo, mesmo que se apresente desacompanhado de outros sinais fisicos e funcionais.

A dificuldade respiratoria após os esforços e com o decubito dorsal mostrava que a massa tumoral fazia sua ação compressora não só sobre as veias, que, diga-se de passagem, são os orgãos mais facilmente atingidos, como tambem sobre a trachea. A estenose da traquea exatamente como acontece com a da veia cava superior, pode se realisar externamente por ação do tumor ou por propagação na sua luz de vegetações neoplasicas. Num ou noutro caso o sintoma dominante é a dispnea, a que Biss empresta um valor altamente significativo, pois diz textualmente: "Em um paciente que apresenta dificuldade respiratoria que não encontra explicação suficiente en alteraçōes cardiacas ou pulmonares deve-se pensar sempre em processo morbido do mediastino". 
Hevisla de Medicina

A dificuldade respiratoria pela compressão da traquea - Lmnquios apresenli, geralmente, unil caracter progressivo chezando a lal ponto de se exteriorisar por cornagem. respiraçuo ruidosa que como veremos na evolução do caso ipareceu alguns dias antes da morte.

() escarro hemoptoico nois o explicnmos pela compressảo alas veias pulmonares. Tän ('ncontrúmus o sinal de OliverCardarelli. nell apresença deste importante sinal argumenInria contra a hipotese de tumor solido que já haviamos formulado, pois autures como Pansini e Litvak encontraram eale sinal nitidamente positivo em tumores mediastinais nio ancurismaticos.

$A$ aurla c os seus ramos graças á sua robusta parede escaparam á compressáo. Isto aliás, é regra, na siudroma que estamos estudando. De fáto, não havia no nosso doente, diferença de amplitude dos pulsos radiais nem diferença da preasio arterial quando tomada, comparativamente, nos dois braços. Tambem não notamos anisocoria, fenomeno, que embora, alguns autores querein explicar pela perturbação do simpalico, parece, hoje, fora de duvida, estar ligada h umu causa arteriosa.

Os nervos, foram no nussu caso, bastante atingidos pelo processo. Como vimos o doente apresentava voz rouca, indicando paralisia unilateral dos musculos adutores da corda vocal; musculos inervados pelo recurrente. Outro sintoma importante, egualmente ligado a perturbação desse mesmo nervo, era a incapacidade que o doente sentia de manter uma convensação prolongada. Isto é devido á perturbação do exfincter glotico que, normalmente, atua como regulador na saida do ar que entretem a vibração das cordas vocais. 0 plexo braquial esternava seu sofrimento pela dor no membro superior direito, principalmente no decubito desse lado, com certeza devido ao deslocamento da massa tumoral.

A tosse na sindroma mediastinal é sintoma que encontra rarias causas para sua produção. Tosse recurrencial, tosse ragal ou losse por irritação e hipersecreção mucosa, devido - comprometimento traqueo-bronquico. No caso concreto, qualquer das causas poderia ser invocada. Existia a perturhaça do recurrente e da traquea, como vimos, e, com toda certeza, lambem do ncrvor vago, pois, a bradicardia evidenciada no exame do aparelho cardio-vascular retratava a irrilacio deste tronco nervoso. 


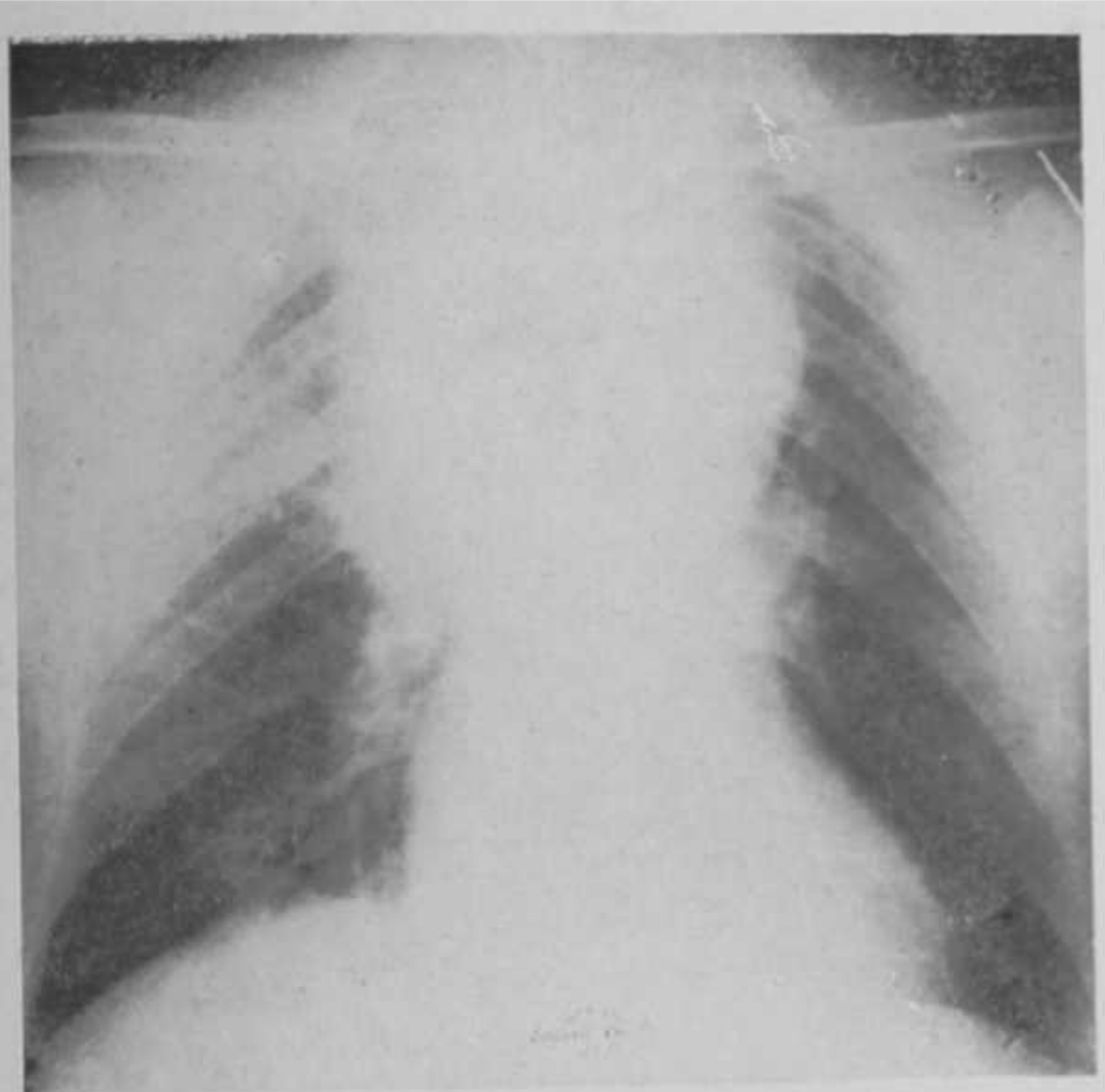

Fig. 5

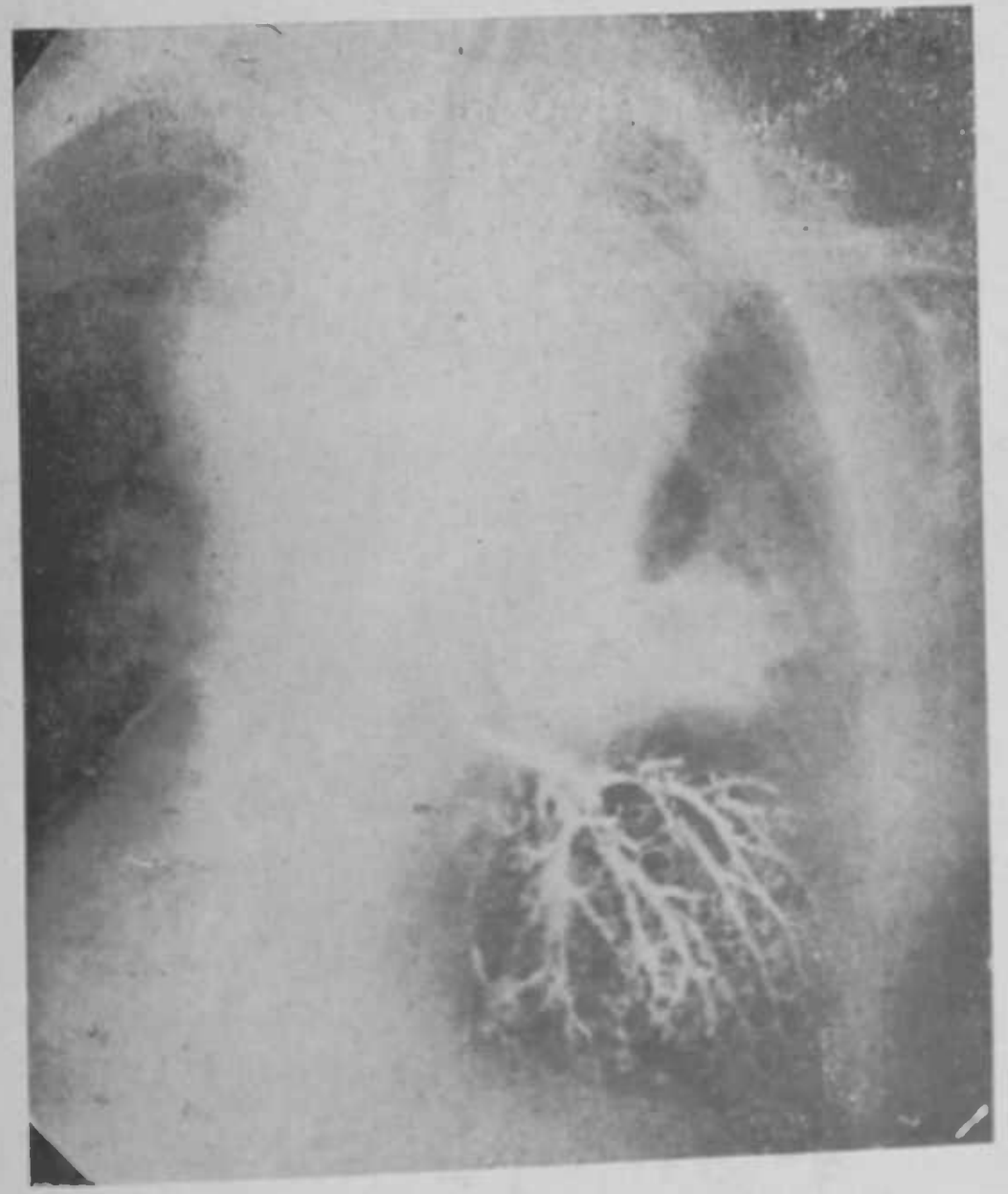

Fig. 6 


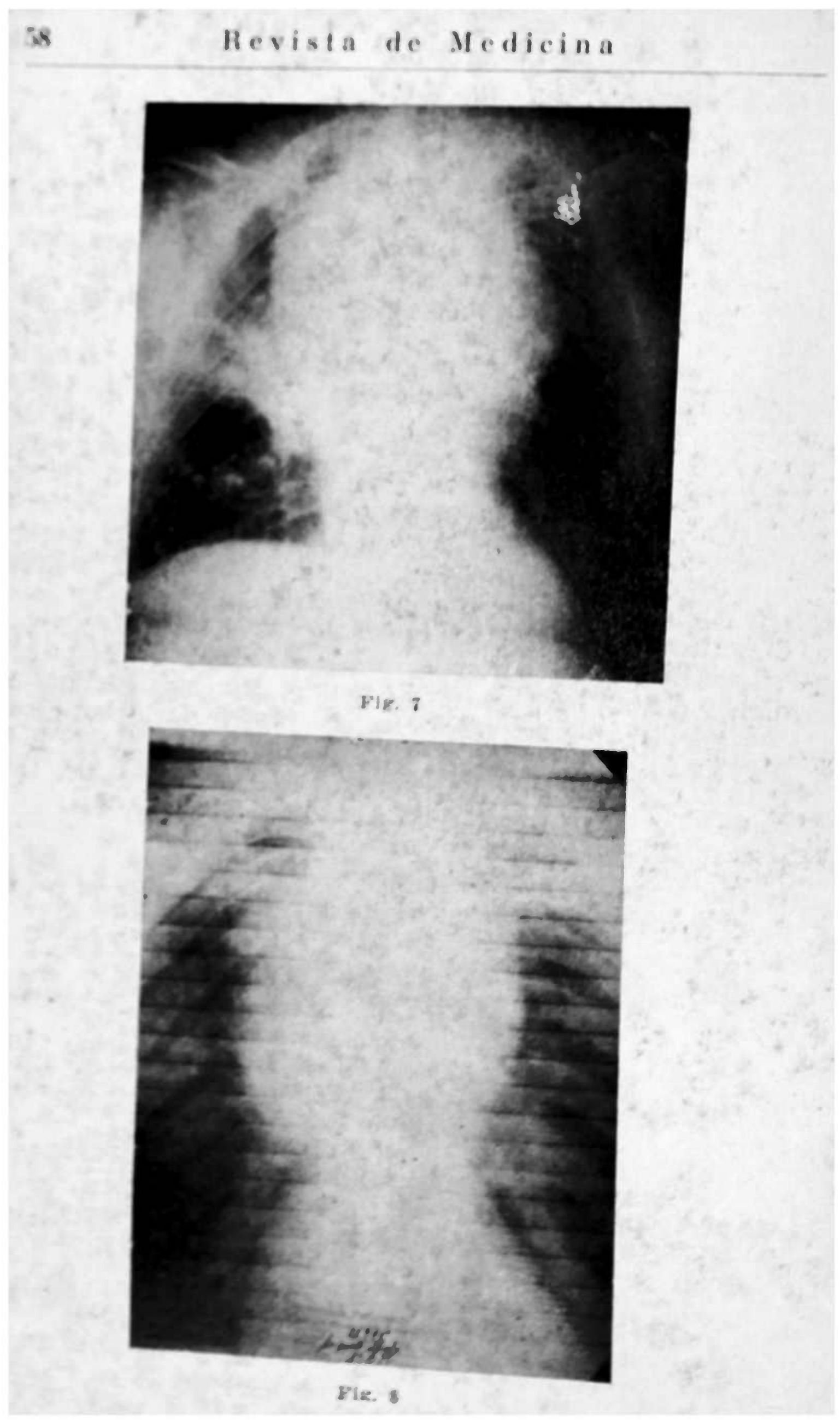


Analizamos deste modo, as perturbações funcionais apresentadas pelo nosso doente. Vejamos, de modo sintetico, o que fornecia a semiologia fisica. Sobre o manubrio esternal a percussão revelara som massiço. Auscultando o cavo oral ao mesmo tempo que se percutia, percebia-se som cavitario. (fig. 2). Como é possivel compreender estes fatos? Normalmente sobre o esterno a percussão obtem um som claro que se degrada ao longo do osso, sendo quasi apagado na base, devido á presença do coração. $O$ desenvolvimento de um tumor retroesternal modifica esta resonancia dando obtusidade percussoria. Quando o tumor ao mesmo tempo que toca a parede esternal, poem-se em contato intimo com a traquea profundamenae, crea novas possibilidades de propagação de sons percussorios, vindo desta maneira, o som a ser audivel na cavidade bucal. Obedecendo ao mesmo determinismo patogenico mas exercido em sentido inverso da traquea para o esterno, explica-se a audibilidade do sopro laringo-traqueal sobre o manubrio. Estes sinais foram todos descritos por Cardarelli no afan de tornar mais acessivel ao clinico a exploração do mediastino. A invasão do campo pulmonar direito trazia os sinais que descrevemos; submacicez com abolição da respiração na fossa infra-clavicular, e submassicez com sopro bronquico no intercapulo direito. Estes dados, entretanto, poderiam traduzir zonas de atelectasias pulmonar com impermeabilidade bronquica na parte anterior (abolição da respiração) e com permeabilidade na parte posterior (sopro bronquico). Nos filiámos á primeira explicação, pois as broncografias realisadas deram imagens normais.

Os exames radiologicos realizados confirmaram plenamente os dados obtidos pela exploração clinica. Senã̃o, vejamos o relatorio do Dr. Paulo de Toledo:

"Tumor solido do mediastino superior e anterior, pretraqueal deslocando a crossa da aorta para a esquerda, de contornos mais ou menos regulares. Condensação pulmonar, de limites difusos ao hilo e no nivel da regiáo infra-clavicular $D . "$

A radiokimografia mostrou que o tumor não pulsava. Havia na sua porção esquerda as pulsações da aorta.

As broncografias a que já nos referimos mostraram boa 
permabilidade bronquica de ambos os lados. (radiografia: (1,5. 5, 6.7, 8 ).

\section{EVOLUÇAO DO CASO}

O deente permaneceu na Enfermaria, trez mezes e meio apruximadnmente. Seu estado gerul foi sempre peiorando aprearntando-se com escarros hemoptoicos quasi todos os dian e, mesmo, an vize's, verdacleiras hemoptises. P'erda de 5 kilos de peso durante o tempo que esteve hospitalisado. Aparrcoram outras lumefaçies ganglionares e se intensificaram a dispnca, a cianose e a braquialgia. Faleceu em verdadeiro estado de usfixia, com forte cornagem. O tratamento usado foi puramente sintomatico pois a radioterapia não trouxe o menor exito.

Para avaliar do crescimento da massa tumoral fizemos posteriormente, outros exames radiologicos, tendo, como é punsivel compurar (radiografias 5 e 7) havido aumento consideravel do tumor. Fste sinal radiologico é o melhor para se avaliar de uma neoplasia maligna.

\section{NECROPSIA DO CASO}

Foi realisada pelo Dr. Constantino Mignone cujo relalorio a seguir transcrevemos (fig. 3 e 4).

\section{REL.ATORIO DA NECROPSIA}

GENERALIDADES: - Cadaver de adulto do sexo masculino, de cór branca. medindo $16,2 \mathrm{cms}$. de comprimento, de compleição merecoberta por emmagrecido. Cabeca regularmente conformada, bras cerradas. Corneas lisos e castanhos, cortados rentes. Palpemente dilatadas. Pelas narings quidos. Dentes em pessimo estadoca e ouvidos nào escorrem liraizes e caries numerosas. Pesco de conservaçảo, apresentando centando ganglios nem cicatrizes. To curto e cylíndrico, nūo aprelerroutaes e frssas supra e infras. Thorax symetrico. Éspaços inAbdomen escarado. Na repiáo inguinal ares pouco pronunciados. chada crural nota-se uma cicatriz linear esuerda, ao nivel da arlensio. acompanhando eas a trahide Orgáos penitaes externos a, sendo de cór branca e re. licalor. Membros regularmente conformas nada mostram de parrecobs. - lace anterior do thorax ormados. Abaixo da pelle que ocdulon. ceado o roaior do tamorax nota-se a presença de alguns 
Revista de Medicina

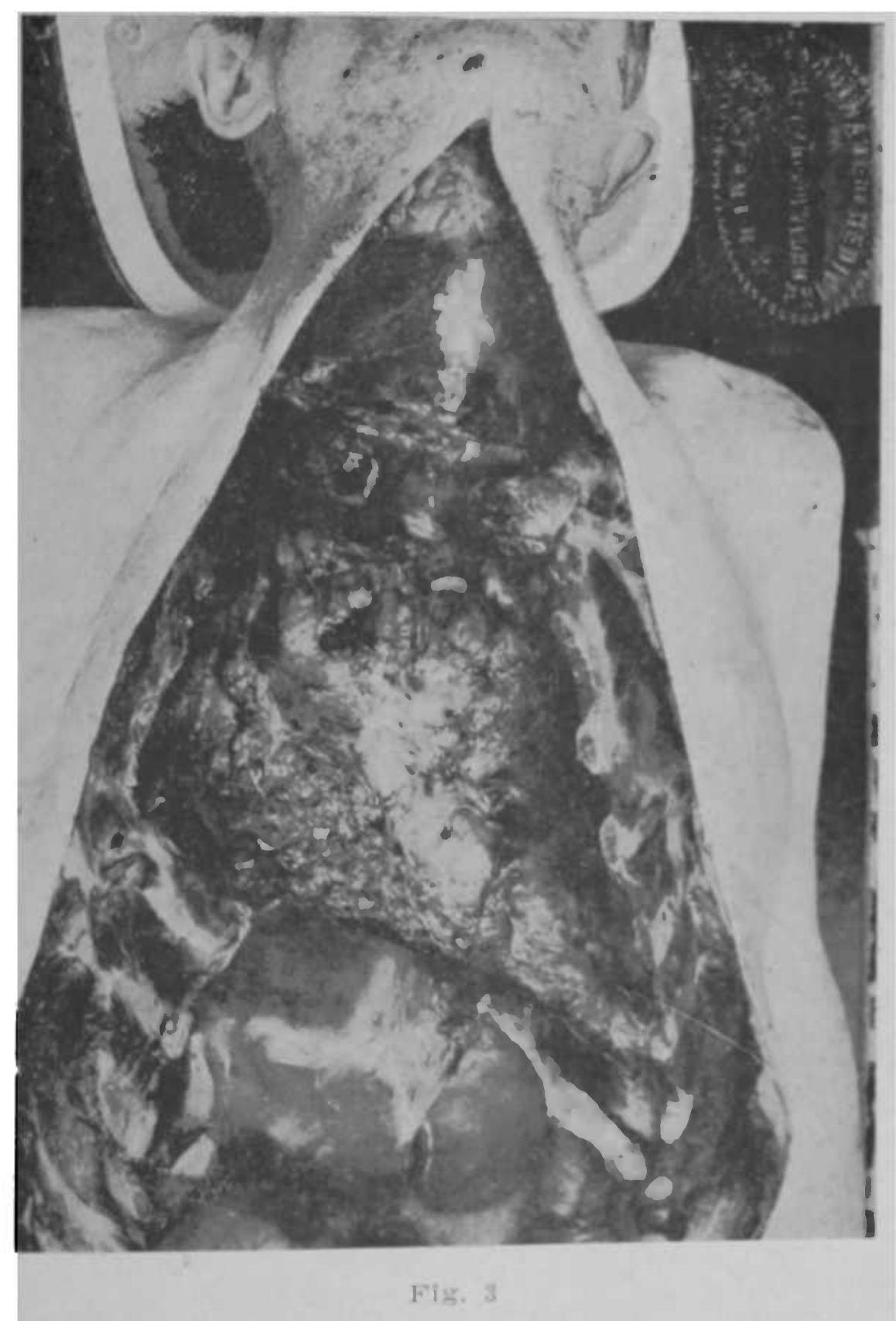




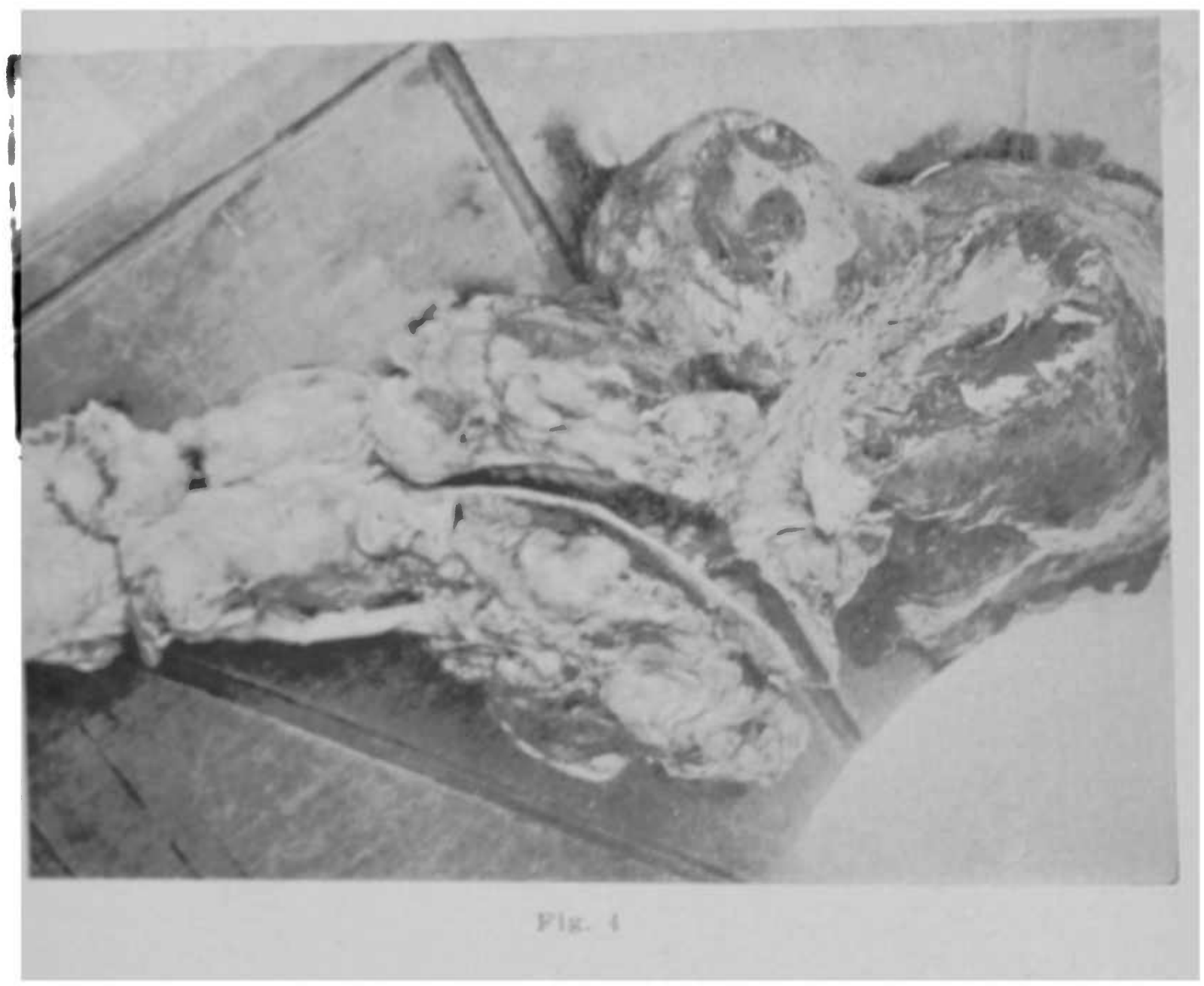


cia dura, moveis, deslisando a pelle livremente sobre os mesmos. Na regiấo inguinal esquerda nota-se a presença de um nodulo sub-cutaneo com as mesmas caracteristicas e do tamanho de um ovo de pomba.

CABECA : - Calota craniaan nada apresenta de particular. Dura-mater e seus seios nada apresentam digno de nota.

ENCEPHALO: - Nada apresenta de particular.

ORGXOS DO PESCOÇO: - Lingua, esophago, pharynge e larỳng: nada apresentam digno de nota.

CAVIDADE THORACICA: - Os pulmões apresentam-se fortemente adherentes em toda a sua extensão. Pericardio liso, brilhante t humido, contendo normal quantidade de liquido. Na base do coraçâo, occupando a parte superior da área cardiaca, mediastinho anterior, na região thymica, observa-se volumosa, massa tumoral de consistencia lenhosa, de superficie externa irregularmente lobulada, de côr branco-amarellada. Por sua face adhere iracamente á face posterior do plastrão external. Lateralmente adhere a pleura mediastinal dos lóbos superiores de ambos os pulmões. Superiormente, tem limites com o bordo inferior da thyroide do qual se separa perfeitamente. Posteriormente envol. ve a trachéa, á qual adhere intimamente ao nivel da sua metade anterior, mais para o lado direito. 0 ramo superior bronchial direito apresenta-se na sua porção inicial com a parede fortemente espessada á custa de uma infiltração neoplasica em sua extensão de mais ou menos 2 cms. estenosando quasi totalmente a sua luz. Este ramo bronchial dahi por diante apresenta a sua parede de aspecto normal, assim como é normal o seu calibre. A mucosa das vias respiratorias em toda a sua extensão se apresenta bem conservada. A aorta thoracica ascendente e grande parte da veia cava superior apresentam-se envolvidas pela massa tumoral; ambos os vasos estão permeaveis. Os cortes frontaes do tumor mostram ser o mesmo constituido por um tecido neoplasico denso, de côr esbranquiçada, salpicado por um fino pontilhado amarellado. Na sua espessura podem-se demilitar áreas redondas de tamanhos variaveis que dão em conjunto ao mesmo, um aspecto lobular. A parede da trachéa é na maior parte de sua extensão bem delimitada sendo em alguns pontos infiltrada pelo mesmo.

PULMKo ESQUERDO: - Pesa 800 grs. Mede $25 \times 18 \times 7 \mathrm{cms}$. Pleura fina e lisa, recoberta na fase anterior do lobo superior por numerosos tractos de adherencias fibrosas rompidas. Nesta face nota-se um pequeno espessamento pleural sob a forma de um nodulo branco amarellado de consistencia dura, medindo $4 \mathrm{~mm}$. de diametro. Superficie externa de côr vermelho-azulada. Consistencia augmentada e crepitação diminuida. A superficie de corte é de côr vermelho-vinhosa, brilhante, de aspecto gelatinoso dando pela expressāo um abundante liquido sanguinolento espumoso. Na espessura da parenchyma pulmonar, ao nivel do bordo anterior, nota-se a presença de 2 nodulos de um tecido denso, homogeneo e esbranquiçado. bem delimitados, medindo respectivamente: 11 e $15 \mathrm{~mm}$. de diametro.

PULMxo DIREITO: - Peso e dimensōes ficam prejudicados devido a conservação de parte do pulmāo, em peça para o lluseu. O 
lobs in'retor apresenla-se inm a pleura recoberla por numernsos parion de altherencial filirosas rompilas. Superficie externa de co al-rerura. Consistencia bastanle nugmentada c crepitacáo dimiauida. A superficie de corte de cor vermelha, brflhante,

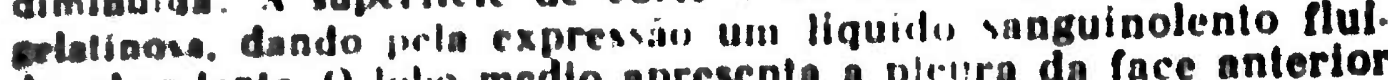
do. atwondonte. () loik) medio apresenta a ple.era da face anterior

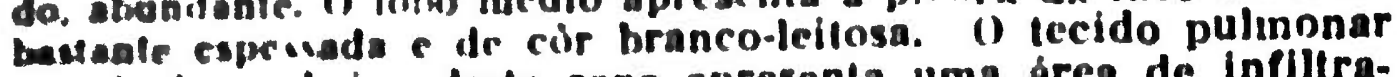
uloudo Ineo abaixo desla zona apresenta uma área de infliliracho aroplanca de forma arredondada, medindo cins. de diametra.

COA 190: - Prsa 300 grs. Forma e volume normaes. Ponta formada a costa do intrirulo esquerdo. Cavidades direltas de canacidade aormal. Tricuspide de aspecto normal e medindo 12 cma. Pulmonar de nspecto normal e medindo $8 \mathrm{cms}$. Myocardio do ventricalo esquirdo de capacidade normal. Bicuspide apreopala a lerinias furlemenle esclerosadas nas bordas livres, mo. diado $11 \mathrm{cmm}$ de circumferencin. A aorla apresenta as lacinias eapenedas e duras inedr $7 \mathrm{cms}$. de circumferencia. Myocardio do rentriculo exquerda de cor castanho escura, medindo 12 mms. de copesourn. Coronarias de aspecto moral.

AOHTA: -.. Hilasicidacle mia. A endarteria upresenta algumas plaras salieales de crir liranco amarellada, na sua porçăo inicial.

CAVIINADE ABINMIIAl.: - Parede abdominal bem desenvolvida. Periluneo liwo, irilhante humido. Epiplon pouco gorduroso - retrahido. Intestinos ligeiramente distendidos por gazes. Appendice excendente externo e livre de adherencias, Baco livre de adbereacias. Vesicula biliar livre de adrherencias. Figado na allura do reburbo costal ao nivel da linha mamilar direita.

PIGado: Pesa 1700 ars. Mede $29 \times 17 \times 9 \mathrm{cms}$. Capsula fina e lisa. Superfirir externa de cór vermelho amarellado, distinguíndo-se pouso nitidamente a estructura lobular. Vesicula hiliar nade apresenta digno de nota.

Baco : Pesa 200 grs. Mede $14 \times 8 \times 6 \mathrm{cms}$. Capsula lina e llsa. Cor cinzento axulada. Consistencia firme. Superficie de corte de cor vermelho, vinhosa, dando pela raspagem misturado e pequena quantidade de polpa.

PANCRE AS: - Forma " rolume normack. Consistencia firme. Superflele de corte de rir roseo antircllada, mostra bem a estruriura lobular do orgio.

ESTOYAco: Sada apresenia digno de nota.

INTESTINOS: - No intestine, delgado nota-se a presença de 2 nodubar alleates, conulituidos por um tecido denso, homogeneo

nix Esotermon wats $\mathrm{cm}$ lod Mede $14 \times 7 \times 7 \mathrm{cms}$. A superficie cxlcrna apre. culser wlentes, extedondado numerosissimos nodulos sub-capdo o dinmetro entre 2 e $20 \mathrm{~mm}$. Esses lima de cir branco thededr corte que? na rona e de consistencia dura. Nia super. 
presença de numerosissimos nodulos de aspesto semelhante aquelle descripto para a superficie external.

SUPRA-RENAL ESQUERDA: - Mede $7 \times 3 \times 3 \mathrm{cms}$. Forma conservada. Superficie externa de côr branco amarellada. Consistencla firme. Ao corte nota-se a substancia cortical da supra renal, constituida por uma fina faixa continua e amarellada, envolvendo u'a massa neoplasica constituida por um tecido, homngeneo e esbranquiçado, lobulado, occupando todo o centro do orgão.

RIM DIREITO: - Mede $14 \times 8 \times 6 \mathrm{cms}$. Caracteres externos e internos semelhantes aos do rim esquerdo.

SUPRA-RENAL DIREITA: - Mede $8 \times 5 \times 5 \mathrm{cms}$. A forma está $b_{\text {.. }}$ :tante alterada apresentando-se o orgão globoso, de superficie externa lisa, salientando-se na face anterior 2 nodulos de aspecto semelhante aos da outra supra-renal. Consistencia dura. Superficie de corte constituida por duas grandes massas de tecido neoplasico denso, homogeneo e esbranquiçado, envolvido por um fino alo amarellado de subsistencia cortical remanescente.

BEXIGA, PROSTATA E TESTICULOS: - Nada apresentam digno de nota.

MOLESTIA: - Endothelioma do mediastino.

DIAGNOSTICOS: - Metastases do endothelioma nas capsulas suprarenaes.

Metastases de endothelioma no intestino delgado.

Metastases de endothelioma nos ganglios inguinaes.

Congestão e edema do pulmão esquerdo. Metastases pulmonares e pleuraes. Pleurite fibrosa.

Congestão e edema do pulmão direito. Metastases de endolbelioma pulmonares. Pleurite fibrosa.

Atrophia fosca do myocardio.

Arteriosclerose incipiente da aorta.

Congestão e hyperplasia da polpa vermelha do baço. - 